\title{
Phase Separation in Garnet Solid Solutions and its Effect on Optical Properties
}

\author{
Shakiba Kaveh, Clément P. Tremblay, Nurhakimah Norhashim, Richard J. Curry, \\ and Anthony K. Cheetham*
}

The use of $\mathrm{Y}_{3} \mathrm{Al}_{5} \mathrm{O}_{12}$ (YAG) doped with $\mathrm{Er}^{3+}$ (YAG:Er ${ }^{3+}$ ) is well established in applications such as planar waveguide amplifiers, ${ }^{[1,2]}$ near-infrared (NIR) lasers for biomedical use, ${ }^{[3-7]}$ and up-conversion phosphors for IR detection by conversion to visible light. ${ }^{[8-10]}$ The YAG:Er ${ }^{3+}$ system has several absorption bands at around 490, 800, 970 and $1480 \mathrm{~nm},{ }^{[11,12]}$ which allows the use of various pumping sources. Although nanoscale inhomogeneity of the $\mathrm{Er}^{3+}$ distribution in YAG has been reported in single crystals, ${ }^{[13]}$ it has long been believed that on a macroscopic scale $\mathrm{Y}_{3} \mathrm{Al}_{5} \mathrm{O}_{12}$ and $\mathrm{Er}_{3} \mathrm{Al}_{5} \mathrm{O}_{12}$ form a complete solid solution over the entire concentration range due to the similar ionic radii of $\operatorname{Er}^{3+}(r=1.004 \AA)$ and $\mathrm{Y}^{3+}(r=1.019 \AA) .{ }^{[14,15]}$ This is convenient because compositions with high $\mathrm{Er}^{3+}$ levels (up to 50 at\%) are of interest for optical applications. ${ }^{[16,17]}$ By contrast, larger rare earths such as $\mathrm{Nd}^{3+}$ have very limited solubility in $\mathrm{YAG}^{[18,19]}$ and are prone to concentration quenching above $\approx 1$ at\%. ${ }^{[20]} \mathrm{YAG}_{\mathrm{E}} \mathrm{Er}^{3+}$ has been manufactured in both polycrystalline ceramic and single-crystal forms. The polycrystalline YAG: $\mathrm{Er}^{3+}$ ceramic is synthesized using a solid-state reaction ${ }^{[21]}$ while the single-crystal form is produced using conventional melt growth such as micro-pulling or the Czochralski method. ${ }^{[22-24]}$ Although the spectroscopic properties and laser performance of $\mathrm{YAG}: \mathrm{R}^{3+}$ ceramics $\left(\mathrm{R}^{3+}=\mathrm{Nd}^{3+}, \mathrm{Er}^{3+}, \mathrm{Yb}^{3+}\right)$ have been shown to be similar to YAG: $\mathrm{R}^{3+}$ single crystals, ${ }^{[14,20,21,25]}$ the ceramic form is much easier to fashion into different shapes and is more cost-effective for certain applications such as lasers and phosphors. In the present work, we have shown that formation of a complete solid solution via solid-state synthesis is dependent upon the heat treatment and erbium content. Using high resolution synchrotron powder XRD patterns, we find phase separation into crystallites with different erbium concentration upon slow cooling from the reaction temperature. This phase separation can be avoided if samples are rapidly quenched to room temperature. The photoluminescence

\footnotetext{
S. Kaveh, C. P. Tremblay, Prof. A. K. Cheetham Department of Materials Science and Metallurgy Cambridge University

Pembroke street, CB2 3QZ, UK

E-mail:akc30@cam.ac.uk

N. Norhashim, Dr. R. J. Curry

Advanced Technology Institute

Department of Electronic Engineering

University of Surrey

Guildford, Surrey, GU2 7XH, UK

N. Norhashim

Universiti Kuala Lumpur

23 Jalan Sultan Ismail, 50250, Kuala Lumpur, Malaysia
}

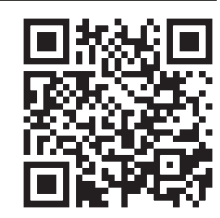

DOI: 10.1002/adma.201302288 spectra of YAG: $\mathrm{Er}^{3+}$ for slow-cooled and fast-quenched samples are presented and the differences in their optical properties are discussed. Phase separation phenomena is not only limited to YAG: $\mathrm{Er}^{3+}$. We have observed phase separation in other similar garnets such as erbium-doped $\mathrm{Y}_{3} \mathrm{Ga}_{5} \mathrm{O}_{12}$, holmium-doped $\mathrm{Y}_{3} \mathrm{Ga}_{5} \mathrm{O}_{12}$ and $\mathrm{Yb}^{3+}$-doped $\mathrm{Er}_{3} \mathrm{Al}_{5} \mathrm{O}_{12}$. These highly unexpected results call for re-analysis of the current understanding of these technologically important materials and we expect will generate a significant body of further studies.

$\left(\mathrm{Y}_{1-\mathrm{x}}, \mathrm{Er}_{\mathrm{x}}\right)_{3} \mathrm{Al}_{5} \mathrm{O}_{12}$ samples $(0.02 \leq \mathrm{x} \leq 0.7)$ were obtained in the first instance by fast quenching from the reaction temperature of $1650{ }^{\circ} \mathrm{C}$. Figure 1 shows a powder X-ray diffraction pattern of quenched YAG: $\mathrm{Er}^{3+}(20 \%)$ obtained using synchrotron radiation. Pure garnet phases were obtained with no impurities, as shown by the good quality of the Rietveld refinements. The inset II of Figure 1 displays the compositional dependence of the lattice parameters in the garnet structure as a function of $\mathrm{Er}^{3+}$ concentration. The solid line indicates the best linear fit as expected from Vegard's law. It is evident that the lattice parameters decrease linearly with increasing $\mathrm{Er}^{3+}$ content due to the smaller ionic radii of $\mathrm{Er}^{3+}$ compared to $\mathrm{Y}^{3+}$. The SEMEDX mapping of YAG: $\mathrm{Er}^{3+}(20 \%)$ displays a homogeneous distribution of erbium and yttrium ions as shown in Figure 2a.

A second set of $\left(\mathrm{Y}_{1-\mathrm{x}}, \mathrm{Er}_{\mathrm{x}}\right)_{3} \mathrm{Al}_{5} \mathrm{O}_{12}$ samples $(0.02 \leq \mathrm{x} \leq 0.7)$ was obtained by slow cooling from the reaction temperature at $1650{ }^{\circ} \mathrm{C}$ with a cooling rate of $10{ }^{\circ} \mathrm{C} \mathrm{min}^{-1}$. Figure 3A displays the synchrotron powder diffraction of slow-cooled YAG:Er ${ }^{3+}$ (20\%). The XRD patterns for slow-cooled YAG:Er ${ }^{3+}$ were examined and, although no impurity phases were observed, the coexistence of two garnet phases with different $\mathrm{Er}^{3+}$ contents can

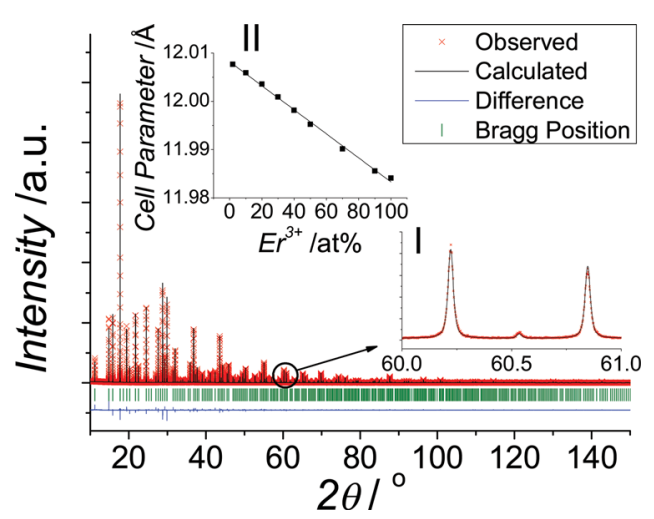

Figure 1. Rietveld refinement based upon the synchrotron powder diffraction of fast-quenched $\mathrm{Y}_{3} \mathrm{Al}_{5} \mathrm{O}_{12} \mathrm{Er}^{3+}(20 \%)$. I) magnified section of XRD pattern II) Lattice parameter vs. $\mathrm{Er}^{3+}$ concentration in fast-quenched $\left(\mathrm{Y}_{1-\mathrm{x},} \mathrm{Er}_{\mathrm{x}}\right)_{3} \mathrm{Al}_{5} \mathrm{O}_{12}(0 \leq \mathrm{x} \leq 1)$ phosphors, which obey Vegard's law. 

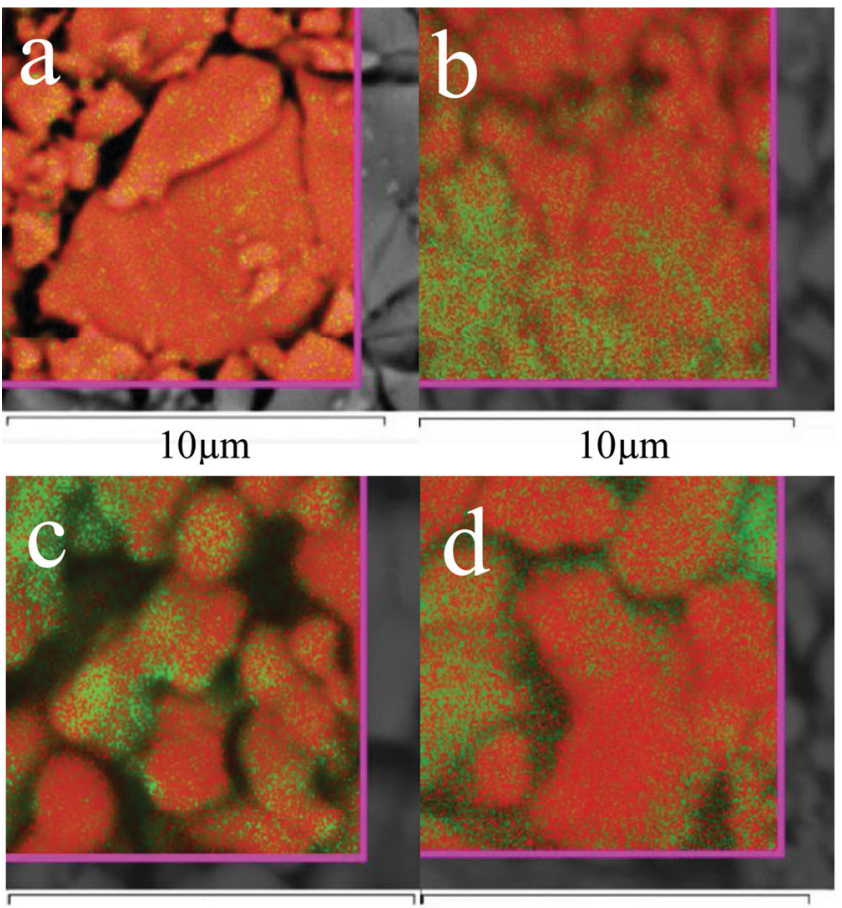

$10 \mu \mathrm{m}$

$10 \mu \mathrm{m}$

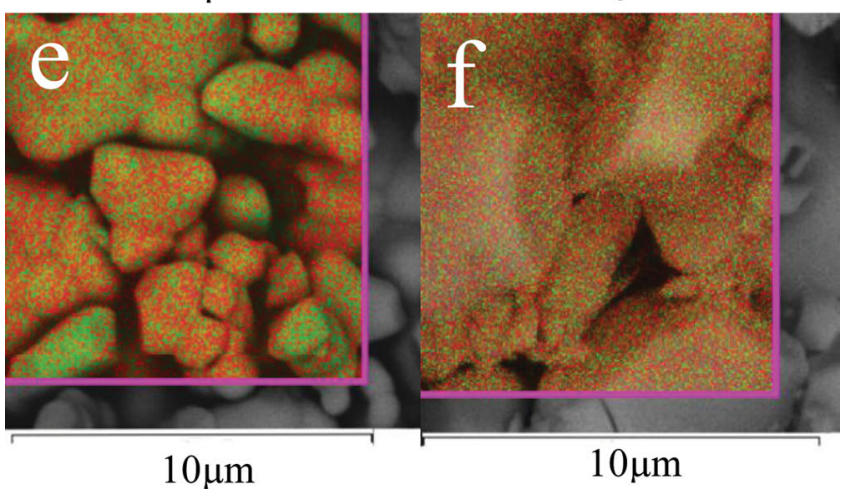

Figure 2. SEM-EDX imaging of a) fast-quenched $\mathrm{Y}_{3} \mathrm{Al}_{5} \mathrm{O}_{12} \cdot \mathrm{Er}^{3+}(20 \%)$ and b) slow-cooled $\mathrm{Y}_{3} \mathrm{Al}_{5} \mathrm{O}_{12}: \mathrm{Er}^{3+}(20 \%)$ from the reaction temperature of $T=1650{ }^{\circ} \mathrm{C}$ and c) $\mathrm{Y}_{3} \mathrm{Ga}_{5} \mathrm{O}_{12:} \mathrm{Er}^{3+}(30 \%)$ fast-quenched from $T=1450{ }^{\circ} \mathrm{C}$ and d) $\mathrm{Y}_{3} \mathrm{Ga}_{5} \mathrm{O}_{12:} \mathrm{Ho}^{3+}(30 \%)$ fast-quenched from $T=$ $1450{ }^{\circ} \mathrm{C}$ e) $\mathrm{Er}_{3} \mathrm{Ga}_{5} \mathrm{O}_{12} \mathrm{Yb}^{3+}(30 \%)$ fast-quenched from $T=1450{ }^{\circ} \mathrm{C}$ and f) $\mathrm{Er}_{3} \mathrm{Ga}_{5} \mathrm{O}_{12:} \mathrm{Yb}^{3+}(30 \%)$ fast-quenched from $\mathrm{T}=1600{ }^{\circ} \mathrm{C}$. The red indicates the distribution of the host ion and green is the dopant distribution.

clearly be seen. Due to the difference between the ionic radii of $\mathrm{Er}^{3+}$ and $\mathrm{Y}^{3+}$, this phase segregation is manifested in the peak splitting of the XRD pattern of slow-cooled erbium-doped YAG samples at high angles.

Figure 3B displays a magnified region of the XRD patterns for slow-cooled $\left(\mathrm{Y}_{1-\mathrm{x}}, \mathrm{Er}_{\mathrm{x}}\right)_{3} \mathrm{Al}_{5} \mathrm{O}_{12}(\mathrm{x}=0,0.1,0.2,0.3$ and 0.5$)$. For reasons of clarity, the calculated patterns have been omitted. It is evident that phase segregation of the garnet phase occurs only for a range of dopant concentration in $\left(\mathrm{Y}_{1-\mathrm{x}}, \mathrm{Er}_{\mathrm{x}}\right)_{3} \mathrm{Al}_{5} \mathrm{O}_{12}$ between $\mathrm{x}=0.08$ and 0.5 (biphasic region). Samples with 50 at\% erbium and higher are monophasic when slow cooled from the reaction temperature. The inset II of Figure 3A shows the compositional dependence of the lattice parameters. The individual phases
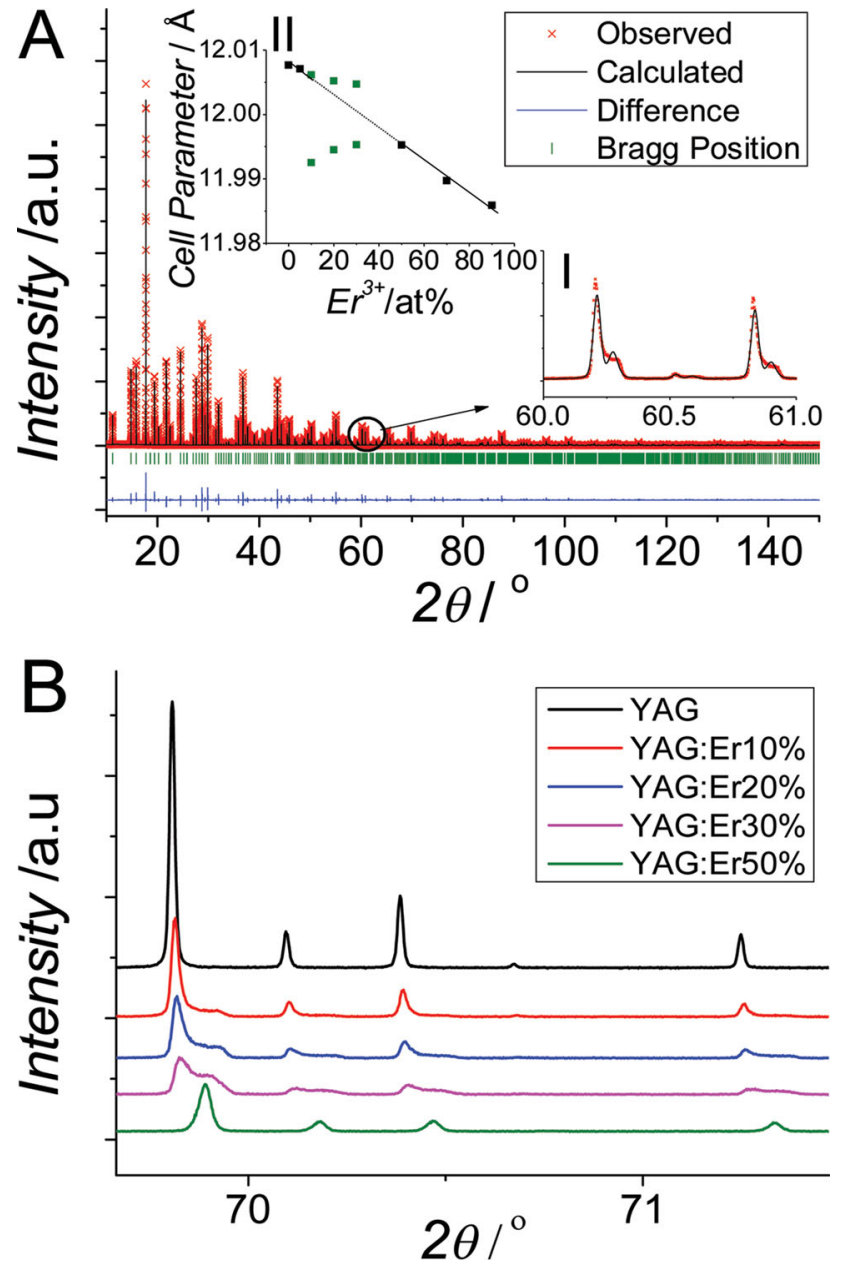

Figure 3. A) Rietveld refinement based upon the synchrotron powder diffraction of slow-cooled $\mathrm{Y}_{3} \mathrm{Al}_{5} \mathrm{O}_{12:} \mathrm{Er}^{3+}(20 \%)$. I) Magnified section of XRD pattern II) Cell parameter vs. $\mathrm{Er}^{3+}$ concentration in slow-cooled $\left(\mathrm{Y}_{1-\mathrm{x}}, \mathrm{Er}_{\mathrm{x}}\right)_{3} \mathrm{Al}_{5} \mathrm{O}_{12}(0 \leq \mathrm{x} \leq 0.9)$ phosphors. B) Magnified synchrotron diffraction pattern of YAG: $\mathrm{Er}^{3+}(\mathrm{x} \%)$ when $\mathrm{x}=0,10,20,30$ and 50 at $\%$.

of the biphasic region were refined and their cell parameters were extracted. The cell parameters in the biphasic region correspond to yttrium-rich and erbium-rich phases and are clearly shown in green dots in the inset II of Figure 3A. Further evidence of phase segregation in the slow-cooled samples can be clearly seen in the SEM-EDX mapping shown in Figure 2b. The results from the Rietveld refinements and SEM-EDX mapping enable us to propose a schematic phase diagram (Figure 4), which describes the phase formation in the $\mathrm{Y}_{3} \mathrm{Al}_{5} \mathrm{O}_{12}-\mathrm{Er}_{3} \mathrm{Al}_{5} \mathrm{O}_{12}$ pseudo-binary system. At $T=1650{ }^{\circ} \mathrm{C}$, the system is monophasic across the complete concentration range when the samples are quenched. However, slow cooling of samples at the yttrium-rich end of the phase diagram leads to phase separation into compositions of approximately 8 and 50 at $\% \mathrm{Er}^{3+}$ in YAG.

The phase segregation observed in slow-cooled YAG: $\operatorname{Er}^{3+}(\mathrm{x})$ for $\mathrm{x}=8 \leq \mathrm{x}<50$ at $\%$, has a profound effect on the excited state inter and intra-atomic dynamics which manifests itself in the optical properties of this system. Figure $\mathbf{5}$ displays the photoluminescence (PL) spectra of fast-quenched and slow-cooled 


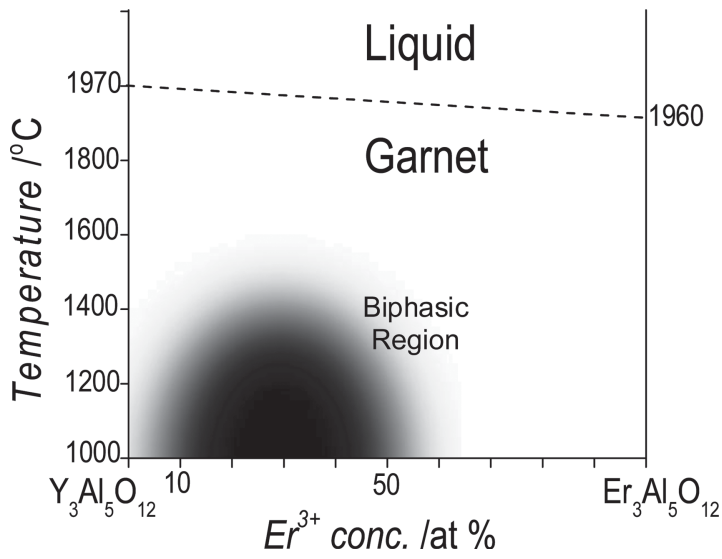

Figure 4. Proposed phase diagram for the $\mathrm{Y}_{3} \mathrm{Al}_{5} \mathrm{O}_{12}-\mathrm{Er}_{3} \mathrm{Al}_{5} \mathrm{O}_{12}$ pseudobinary system. The shaded part corresponds to the approximate extent of the biphasic region.

YAG: $\operatorname{Er}^{3+}(20$ at\%) upon excitation at $488 \mathrm{~nm}$ at $T=300 \mathrm{~K}$ and $80 \mathrm{~K}$. It is clear that the cooling procedure of the two samples with equivalent amount of erbium has drastically affected their PL behavior. At $T=300 \mathrm{~K}$, the two samples display almost identical emission behavior in the $500 \mathrm{~nm}$ to $1100 \mathrm{~nm}$ region. However, in the 1200-1700 $\mathrm{nm}$ region, it is clear that the slowcooled sample displays an increase in PL by a factor of $\approx 3$. This arises due to the phase segregation present in this sample as described in the previous paragraph. It is interesting to note that in slow-cooled YAG: $\mathrm{Er}^{3+}(20 \%)$, approximately $70 \%$ of the crystallites are erbium-deficient and contain only around 8 at\% erbium. The differences in the intensities are also reflected in the PL lifetimes. For example, the room temperature lifetimes of the emission centered at $1535 \mathrm{~nm}$ for slow-cooled and fastquenched YAG: $\mathrm{Er}^{3+}(20 \%)$ under $488 \mathrm{~nm}$ excitation were found to be $\tau \approx 2.71 \mathrm{~ms}$ and $\tau \approx 1.14 \mathrm{~ms}$ respectively.

The contrast between the PL spectra of the two samples is even more dramatic at $T=80 \mathrm{~K}$. As we can see from Figure 5B, fast-quenched YAG: $\mathrm{Er}^{3+}(20 \%)$ displays an increase of around an order of magnitude in the 500-900 nm emission intensity, but a significant decrease in the intensity of emissions above $1600 \mathrm{~nm}$ compared to the slow-cooled sample. The origin of these differences is linked to complex interactions in these systems which will be the subject of a follow-up paper.

In light of the dramatic effects on phase segregation in the YAG-ErAG system, it is clearly of importance to establish whether this is a common phenomenon in garnet solid solutions containing the smaller rare-earths or yttrium. We have therefore examined a limited number of related systems in an initial exploration of this question. First, we have looked at the gallium analogue of $\mathrm{YAG}: \mathrm{Er}^{3+} .{ }^{[26]}\left(\mathrm{Y}_{0.7}, \mathrm{Er}_{0.3}\right)_{3} \mathrm{Ga}_{5} \mathrm{O}_{12}\left(\mathrm{YGG}: \mathrm{Er}^{3+}\right)$ was synthesized via solid-state synthesis as outlined in the experimental section. This composition was chosen since phase separation has been dominant at this composition in YAG:Er ${ }^{3+}$. When the YGG: $\mathrm{Er}^{3+}(30 \%)$ is synthesized directly at $1450{ }^{\circ} \mathrm{C}$ and fast quenched, it shows clear evidence of phase segregation by both synchrotron PXRD (Figure S4) and EDX, as shown in Figure 2c.

We estimate that the upper and lower limits of the two phase region are approximately the same as those for the YAG
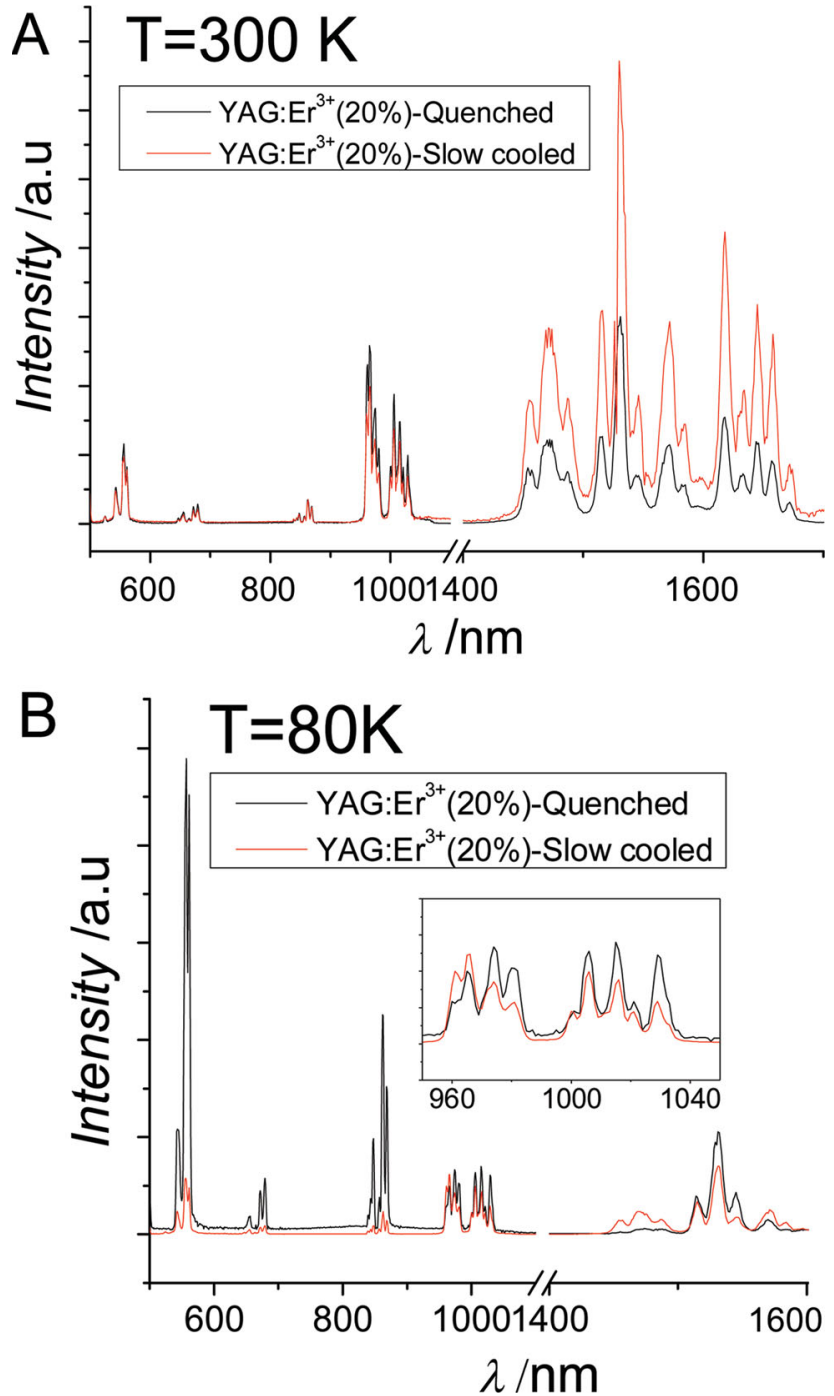

Figure 5. Photoluminescence spectra under $\lambda=488 \mathrm{~nm}$ excitation comparing fast-quenched and slow-cooled $\left(\mathrm{Y}_{0.8}: \mathrm{Er}_{0.2}\right)_{3} \mathrm{Al}_{5} \mathrm{O}_{12}$ samples at A) room temperature and $B$ ) $T=80 \mathrm{~K}$, the inset displays the magnified NIR emission band.

system, i.e., $\approx 8$ at $\%$ and $\approx 50$ at $\% \mathrm{Er}^{3+}$ respectively. However, if the sample is synthesized at $1600{ }^{\circ} \mathrm{C}$, it is monophasic and does not phase separate on slow cooling; this must reflect a difference in the kinetics between the YAG and YGG systems, perhaps due to differences in the peak temperature of the biphasic region that is illustrated for the YAG: $\mathrm{Er}^{3+}$ system in Figure 4.

We have also investigated phase separation in $\left(\mathrm{Y}_{0.7}, \mathrm{Ho}_{0.3}\right)_{3} \mathrm{Ga}_{5} \mathrm{O}_{12}\left(\mathrm{YGG}: \mathrm{Ho}^{3+}\right)$. In this system the difference in lattice parameters is too small for phase separation to be detected by PXRD, even with synchrotron data. However, the SEM-EDX mapping in Figure $2 d$ clearly shows phase segregation in YGG: $\mathrm{Ho}^{3+}(30 \%)$ fast quenched from $1450{ }^{\circ} \mathrm{C}$. Again, however, the system is monophasic when the samples are fast quenched from $1600{ }^{\circ} \mathrm{C}$. The overall picture is very similar to both the YAG: $\mathrm{Er}^{3+}$ and YGG: $\mathrm{Er}^{3+}$ systems.

Finally, we have explored the question as to whether the phase separation is characteristic of systems containing a rare-earth in 
combination with yttrium (which is not a rare-earth) or might occur in systems containing only rare-earths. To this end, we have examined the system $\mathrm{Er}_{3} \mathrm{Ga}_{5} \mathrm{O}_{12}-\mathrm{Yb}_{3} \mathrm{Ga}_{5} \mathrm{O}_{12}$ where the ionic radius difference is similar to that in YGG-ErGG system $\left(\mathrm{r}_{\mathrm{Er}}{ }^{3+}=1.004 \AA\right)$ and $\left(\mathrm{r}_{\mathrm{Yb}}{ }^{3+}=0.985 \AA\right) . \mathrm{Er}_{3} \mathrm{Ga}_{5} \mathrm{O}_{12}: \mathrm{Yb}^{3+}(30 \%)$ shows biphasic behavior when fast quenched from $1450{ }^{\circ} \mathrm{C}$, as manifested in the EDX mapping as shown in Figure 2e. It is monophasic when fast quenched from $1600^{\circ} \mathrm{C}$ (Figure 2f).

In summary, phase segregation has been found at rather high temperatures in all the garnet systems studied. The effect is clearly apparent in high resolution synchrotron XRD data, but is difficult to observe with laboratory X-rays. Such behavior is highly unexpected, given the very small size differences between the cations involved. Note that the segregation is always seen to occur at the end of the phase diagram associated with the larger of the two $\mathrm{Ln}^{3+} / \mathrm{Y}^{3+}$ cations. We anticipate that phase separation occurs widely in garnet systems but we do not believe that it is related to the occurrence of rare-earth antisites, which have been observed in a number of melt-grown crystals and ceramics. ${ }^{[27-29]}$ It would be of interest to explore whether the optical properties of transparent ceramics and single crystals can be affected and even controlled by the cooling protocol for samples that fall in this composition range. In addition, phase separation may even affect the magnetic properties of iron-based garnets such as $\left(\mathrm{Y}_{3-\mathrm{x}}, \mathrm{Ln}_{\mathrm{x}}\right) \mathrm{Fe}_{5} \mathrm{O}_{12}$. Further work is clearly needed in this area.

\section{Experimental Section}

Synthesis: Samples of $\left(\mathrm{Y}_{1-\mathrm{x}}, \mathrm{Er}_{\mathrm{x}}\right)_{3} \mathrm{Al}_{5} \mathrm{O}_{12}$ phosphors $(0.0 \leq \mathrm{x} \leq 0.7)$, $\left(\mathrm{Y}_{0.7}, \mathrm{Ho}_{0.3}\right)_{3} \mathrm{Ga}_{5} \mathrm{O}_{12}, \quad\left(\mathrm{Y}_{0.7}, \mathrm{Er}_{0.3}\right)_{3} \mathrm{Ga}_{5} \mathrm{O}_{12}$ and $\left(\mathrm{Er}_{0.7}, \mathrm{Yb}_{0.3}\right)_{3} \mathrm{Al}_{5} \mathrm{O}_{12}$ were prepared using conventional solid-state synthesis. Stoichiometric amounts of $\mathrm{Y}_{2} \mathrm{O}_{3}, \mathrm{Al}_{2} \mathrm{O}_{3}, \mathrm{Ho}_{2} \mathrm{O}_{3}, \mathrm{Er}_{2} \mathrm{O}_{3}, \mathrm{Yb}_{2} \mathrm{O}_{3}$ and $\mathrm{Ga}_{2} \mathrm{O}_{3}$ were ground and mixed in an agate mortar. The aluminum garnet underwent multiple sintering stages at $1350{ }^{\circ} \mathrm{C}$ (10 hours), $1400^{\circ} \mathrm{C}$ (10 hours) and finally $1650{ }^{\circ} \mathrm{C}$ for 24 hours with intermediate grinding stages. The gallium garnet underwent two heating stages at $1450{ }^{\circ} \mathrm{C}$ (10 hours) and $1600{ }^{\circ} \mathrm{C}$ (10 hours). One set of samples was quenched rapidly from the reaction temperature whilst the other set was slowly cooled at a rate of $10^{\circ} \mathrm{C} \mathrm{min}^{-1}$

Characterization: The $\mathrm{Y}^{3+}$ contents in $\mathrm{YAG}: \mathrm{Er}^{3+}$ samples were verified using Inductively Coupled Plasma-Atomic Emission Microscopy (ICP-AES) (Table S2). High resolution synchrotron X-ray powder diffraction patterns were obtained using beamline 111 at the Diamond Light Source UK. A 45 analyzer crystal array MAC detector was used with a mean wavelength of 0.82696 (1) $\AA$, calibrated using a Si NIST 640C standard. Samples were held in $0.3 \mathrm{~mm}$ glass capillaries, which were rotated continuously during the measurement to reduce the effects of preferred orientation. For analysis, data binnings of $0.002^{\circ}$ were used. Rietveld refinements ${ }^{[30]}$ were all performed using the CSAS program. ${ }^{[31]}$

Samples were prepared for secondary electron microscopy (SEM) and energy dispersive X-ray (EDX) analysis by placing a pressed pellet on an adhesive carbon tape attached to an aluminum stub. This was then coated with gold nanoparticles $(\approx 15 \mathrm{~nm}$ ) using an Emitech $\mathrm{K} 575$ sputter coater to prevent charging effects. SEM images were taken using a JEOL 5800 LV microscope. This was equipped with an Oxford Instruments Inca Penta FETx3 system which was used for EDX analysis.

$\mathrm{PL}$ spectra were recorded using pressed pellets of each sample mounted inside a cryostat with fused silica windows providing optical access (Oxford Instruments Optistat DN-V). Samples were excited at $488 \mathrm{~nm}$ using a Nd:YAC pumped OPO (Spectra Physics Quanta-Ray and versaScan) pulsed excitation source with a repetition rate of $21 \mathrm{~Hz}$, a pulse width $\sim 8 \mathrm{~ns}$, and an average power of $5.6 \mathrm{~mW}$. PL data were collected using appropriate optics and dispersed in a monochromator (Bentham TMc300, $1200 \mathrm{~g} \mathrm{~mm}^{-1}$ and $600 \mathrm{~g} \mathrm{~mm}^{-1}$ grating) prior to detection using Si or InGaAs photodiodes (Newport 818-SL and 818-IG respectively). The detected signal was processed using lock-in amplification (Signal Recovery 7265). Long pass and short pass interference filters were used to prevent detection of the excitation wavelength, OPO idler, and any $2^{\text {nd }}$ order grating reflections. All spectra were corrected for the spectral response of the system. PL lifetimes were recorded using the same excitation and $\mathrm{PL}$ collection system as used for the PL spectral studies. Detection was undertaken using visible and NIR PMT detectors (Bentham DH-3 and Hamamatsu R5509-72 respectively) and signal transients recorded using a digital oscilloscope (Agilent Infiniium $1 \mathrm{GHz}, 4 \mathrm{GSa} / \mathrm{s}$ ). The measured system response was of the same order as the excitation pulse width.

\section{Supporting Information}

Supporting Information is available from Wiley Online Library or from the author.

\section{Acknowledgements}

The author wishes to thank Dr. Julia Parker and Prof. Chui Tang at Diamond 111 beamline for assistance with the synchrotron measurements. S. Kaveh thanks the EPSRC for a studentship.

Received: May 20, 2013

Revised: August 5, 2013

Published online:

[1] C. G. Atkins, J. F. Massicott, J. R. Armitage, R. Wyatt, B. J. Ainslie, S. P. Craig-Ryan, Electron. Lett. 1989, 25, 2-3.

[2] M. Nishi, S. Tanabe, K. Fujita, K. Hirao, J. Alloys Compd. 2006, 408412, 788-790.

[3] S. A. Payne, L. L. Chase, L. K. Smith, W. L. Kway, W. F. Krupke, IEEE J. Quantum Electron. 1992, 28, 2619-2630.

[4] C. Greskovich, J. Appl. Phys 1973, 44, 4599-4606.

[5] M. Eichhorn, S. T. Fredrich-Thornton, E. Heumann, G. Huber, Appl. Phys. B: Lasers Opt. 2008, 91, 249-256.

[6] J. Zhou, W. Zhang, T. Huang, L. Wang, J. Li, W. Liu, B. Jiang, Y. Pan, J. Guo, Ceram. Int. 2011, 37, 513-519.

[7] S. Georgescu, O. Toma, I. Ivanov, J. Lumin. 2005, 114, 43-52.

[8] H. Xu, Z. Dai, Z. Jiang, Eur. Phys. J. D 2001, 83, 79-83.

[9] L. Min, W. Shiwei, J. Zhang, L. An, C. Lidong, J. Rare Earths 2006, 24, 732-735

[10] F. E. Auzel, Proc. IEEE 1973, 61, 758-786.

[11] J. A. Koningstein, J. E. Geusic, Phys. Rev. 1964, 726, 726-728.

[12] G. Huber, J. Koeke, Appl. Phys. B: Lasers Opt 1995, 158, 151-158.

[13] O. V Karban, S. N. Ivanov, E. I. Salamatov, S. G. Bystrov, Inorg. Mater. 2001, 37, 711-717.

[14] J. B. Gruber, A. S. Nijjar, D. K. Sardar, R. M. Yow, C. C. Russell, T. H. Allik, B. Zandi, J. Appl. Phys. 2005, 97, 063519-1-8.

[15] R. D. Shannon, C. T. Prewitt, Acta Cryst. 1969, 25, 925-946.

[16] W. Q. Shi, M. Bass, M. Birnbaum, J. Opt. Soc. Am. B 1990, 7, 1456.

[17] M. Pokhrel, G. A. Kumar, P. Samuel, K. I. Ueda, T. Yanagitani, H. Yagi, D. K. Sardar, Opt. Mat. Express 2011, 1, 119-125.

[18] A. Ikesue, Y. L. Aung, T. Taira, T. Kamimura, K. Yoshida, G. L. Messing, Annu. Rev. Mater. Res 2006, 36, 397-429.

[19] V. I. Chani, G. Boulon, W. Zhao, T. Yanagida, A. Yoshikawa, Jpn. J. Appl. Phys. 2010, 49, 075601. 
[20] J. Lu, M. Prabhu, J. Song, C. Li, J. Xu, K. Ueda, A. A. Kaminskii, H. Yagi, T. Yanagitani, Appl. Phys. B: Lasers Opt. 2000, 71, 469-473.

[21] T. Taira, I. Paper, IEEE J. Sel. Top. Quantum Electron. 2007, 13, 798-809.

[22] F. Cornacchia, M. Alshourbagy, A. Toncelli, M. Tonelli, H. Ogino, A. Yoshikawa, T. Fukuda, J. Cryst. Growth. 2005, 275, 534-540.

[23] Y. Yu, Z. Wu, S. Zhang, J. Alloys Compd. 2000, 302, 204-208.

[24] M. Sugiyama, Y. Yokota, Y. Fujimoto, T. Yanagida, Y. Futami, S. Kurosawa, A. Yoshikawa, J. Cryst. Growth 2012, 352, 110-114.

[25] V. Lupei, Opt. Mater. (Amsterdam, Neth.) 2009, 31, 701-706.
[26] V. F. Popova, A. G. Petrosyan, E. a. Tugova, D. P. Romanov, V. V. Gusarov, Russ J. Inorg. Chem. 2009, 54, 624-629.

[27] A. Lupei, V. Lupei, E. Osiac, J. Phys. Condens. Matter 1998, 10, 9701-9710.

[28] V. Lupei, A. Lupei, A. Ikesue, Opt. Mater. 2008, 30, 17811786.

[29] V. Lupei, A. Lupei, S. Georgescu, B. Diaconescu, T. Taira, Y. Sato, S. Kurimura, A. Ikesue, J. Opt. Soc. Am. B 2002, 19, 360-368.

[30] H. M. Rietveld, J. Appl. Crystallogr. 1969, 2, 65-71.

[31] A. C. Larson, R. B. Von Dreele, Report LAUR 1994, 86-748. 